\title{
Intralesional steroid and ultrasound therapy in patients with carpal tunnel syndrome
}

\author{
Md. Israt Hasan and Syed Mozaffar Ahmed
}

\begin{tabular}{|c|c|}
\hline \multicolumn{2}{|l|}{ Article Info } \\
\hline \multicolumn{2}{|c|}{$\begin{array}{l}\text { Department of Physical Medicine and } \\
\text { Rehabilitation, Faculty of Medicine, } \\
\text { Bangabandhu Sheikh Mujib Medical } \\
\text { University, Shahbag, Dhaka, Bangladesh }\end{array}$} \\
\hline \multicolumn{2}{|c|}{$\begin{array}{l}\text { For Correspondence: } \\
\text { Md. Israt Hasan } \\
\text { isratpmr@gmail.com }\end{array}$} \\
\hline Received: & 21 October 2019 \\
\hline Accepted: & 15 November 2019 \\
\hline Available Online: & 23 December 2019 \\
\hline
\end{tabular}

ISSN: 2224-7750 (Online)

2074-2908 (Print)

DOI: $10.3329 /$ bsmmuj.v12i4.44051

Keywords: Carpal tunnel syndrome Steroid therapy; Ultrasound

Cite this article:

Hasan MI, Ahmed SM. Intralesional steroid and ultrasound therapy in patients with carpal tunnel syndrome Bangabandhu Sheikh Mujib Med Univ J. 2019; 12: $177-181$

Copyright:

The copyright of this article is retained by the author(s) [Atribution CC-By 4.0]

Available at:

www.banglajol.info

A Journal of Bangabandhu Sheikh Mujib Medical University, Dhaka, Bangladesh
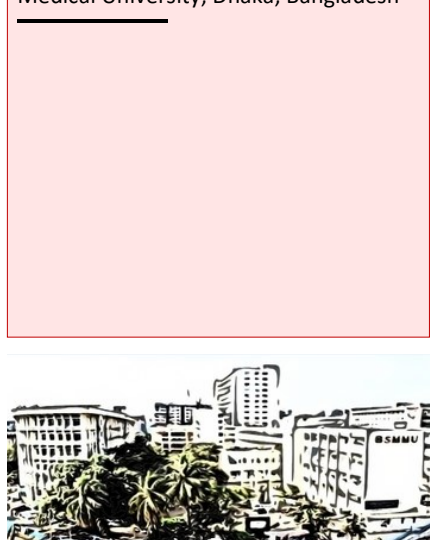

\section{Abstract}

The study aimed to compare the effects of intralesional steroid injection and ultrasound therapy for the treatment of carpal tunnel syndrome. A total 130 patients divided into 2 groups: a) One group $(n=65)$ received intralesional corticosteroid injection along with wrist splint, exercise, naproxen sodium $500 \mathrm{mg}$ tablet and omeprazole $20 \mathrm{mg}$ capsule twice daily for 2 weeks; b) Another group received $(n=65)$ ultrasound therapy $(10 \mathrm{~min} /$ day, 3 days/ week for 4 weeks) along with Wrist splint for 4 weeks, exercises for 4 weeks, naproxen sodium $500 \mathrm{mg}$ tablet and omeprazole $20 \mathrm{mg}$ capsule twice daily for 2 weeks. The patients were followed-up 2 weekly for 4 weeks. The visual analogue score, symptom severity scores and functional status scores were significantly improved within each group at week 2 $(p<0.05)$ and week $4(p<0.05)$ except for the symptom severity score at $(p>0.05)$. The improvement in symptom severity scores and functional status scores in the intralesional steroid group was more than in the ultrasound therapy group after 4 weeks.

\section{Introduction}

Carpal tunnel syndrome is the most common form of entrapment neuropathy caused by the compression of the median nerve as it passes through the carpal tunnel.

The management is based on relieving the pressure on the median nerve with various conservative and surgical treatment methods. However, clinicians strive to build up conservative or less invasive methods. This trend is likely due to three main reasons: a) the recurrence rate of surgical treatment, $\underline{1}$ b) less complication with conservative treatment and c) some patients with carpal tunnel syndrome have spontaneous recovery. 2

Mild to moderate symptoms are commonly managed with conservative measures. 3 Nonsurgical treatment for carpal tunnel syndrome include wrist splinting, steroid injecttion into the carpal canal, exercises, yoga, therapeutic ultrasound, activity or ergonomic modification and oral medication of vitamins. $\underline{4}$

There are many options of treatment. $\underline{5}$ Steroid injection into the carpal tunnel is easy to perform, and the rate of complications is low. In addition, response to the treatment may confirm the diagnosis. Local corticosteroid injection is effective in the short-term treatment of musculoskeletal problems including carpal tunnel syndrome $\underline{6-8}$. Iatrogenic injury to the median nerve is a major complication and the safest location for the injection is highly debated. $.9,10$

Therapeutic ultrasound is a physical therapy that involves the application of a roundheaded instrument to the skin of the painful area to deliver sound waves that are absorbed by the underlying connective tissue, such as ligaments and tendons. $\underline{11}$ The intervention can vary in its intensity and frequency of sound waves, and the duration of treatment can range from a few days to months. Ultrasound is a widely used and accepted adjunct modality for the management of many musculoskeletal conditions, particularly lesions of tendon, ligament and bursa. $\underline{12,13}$ Therapeutic ultrasound is reported to reduce the edema, relieve pain and accelerate tissue repair.14. Analgesia that is induced by therapeutic ultrasound may be the result of increased capillary permeability and tissue metabolism, the enhancement of fibrous tissue extensibility and the elevation of the pain threshold by thermal mechanisms. $\underline{15,16}$ Therapeutic ultrasound is also used to treat a 
number of musculoskeletal conditions, such as osteoarthritis and acute ankle sprain. $\underline{17}$

Splinting creates immobilization of the wrist joint by an external device. The splint usually leaves the fingers and thumb free to move and it may be worn at nighttime, or at night and during daytime activities that cause wrist motion. A thermoplastic splint may be custom-fitted to the patient by an occupational therapist, or a softer, adjustable splint may be fitted and purchased. A specific soft splint that prevents the wrist from moving into flexion, and maintains the long and ring fingers in extension at the metacarpophalangeal and interphalangeal joints, called the 'MANU' hand brace, is commercially made. $\underline{18}$

\section{Materials and Methods}

The study was conducted from July 2017 to June 2018. On arrival of the patient, the history, physical examination and investigation were done. The subjects were selected according to the inclusion criteria: a) age $\geq 18$ years; b) patients with complaints of paresthesia and/or pain for at least one month in all or part of the hand territory innervated by the median nerve mainly at night or on waking and/or triggered by certain postures or repetitive forced movements of the fingers or wrist; c) electrophysiological evidence of median nerve entrapment at the wrist; d) no evidence of joint infection, recent trauma, fracture, malignancy, tuberculosis; e) no history of heat sensitivity or skin lesion and f) stable level of activity and would continue the treatment as directed.

In total 158 patients were selected according to the criteria and divided into two groups randomly by the way of lottery manually: a) one group $(n=80)$ received intralesional corticosteroid injection (Trialone $20 \mathrm{mg} / \mathrm{mL}$ from Drug International Ltd, Bangladesh) along with wrist splint, exercise for 4 weeks, naproxen sodium 500 tablet and omeprazole $20 \mathrm{mg}$ capsule twice daily for 2 weeks; b) Another group received $(n=78)$ ultrasound therapy (10 $\mathrm{min} /$ day, 3 days/week for 4 weeks) along with wrist splint for 4 weeks, exercises for 4 weeks, naproxen sodium $500 \mathrm{mg}$ tablet and omeprazole $20 \mathrm{mg}$ capsule twice daily for 2 weeks. The patients were followed-up 2 weekly for 4 weeks.

The patients received intralesional steroid injection $(20 \mathrm{mg} / \mathrm{mL})$ in a single wrist on the carpal tunnel. The patients received continuous ultrasound using Enraf Nonius Sonoplus operated at a frequency of $1 \mathrm{MHz}$ and intensity of $1.5 \mathrm{~W} / \mathrm{cm}^{2}$ with a transducer of $5 \mathrm{~cm}^{2}$ and with aquasonic gel as couplant. The machine was standardized initially, and the output was controlled regularly on a simple underwater radiation balance. Slow circular movements applied by the transducer head over the wrist for $10 \mathrm{~min} /$ day 3 days/week for 4 weeks. The duration of ultrasound application estimated for each patient using Grey's formula as follows:

Total treatment time $=$ Planned local exposure time $x$ (tissue area/effective radiating area)

Ultrasound therapy was given and exercise was shown by a physiotherapist.

Among the 158 patients, 28 were dropped out (15 from the intralesional steroid group and 13 from the ultrasound therapy group) because they could not follow the allocated treatment regularly. Ultimately 130 patients (52 males, 78 females) followed the treatment regularly.

\section{Data collection procedure:}

After the treatment of the patients as per schedule, the patients were assessed at baseline, week 2 , week 4 after the starting of treatment and the outcome recorded in the assessment datasheet. Assessment of the patient was done by Boston Questionnaire, $\underline{\underline{19}}$ and visual analog score (VAS). The data were recorded properly in the data schedule.

\section{Statistical analysis}

All data were analyzed using SPSS-22 software. The results expressed as a percentage and mean $\pm S D$ and $p<0.05$ considered as the level of significance. Comparison of continuous variables between the two groups made with Student's ttest for measuring independent data.

\section{Results}

Table I shows the comparison of VAS score between two groups at different time points. In Group A, at baseline, the mean VAS score was 6 which decreased gradually to 3.3 (at week 2) and then 2.7 (at week 4). In Group B, at baseline, the mean VAS score was 6.4 which decreased gradually to 4.4 (at week 2) and then 3.2 (at week 4). At the initial stage there was no statistical difference between two groups ( $p>0.05)$. But in week 2 and 4 , there were highly significant statistical difference $(\mathrm{p}<0.05)$.

The mean symptom severity score at baseline was 3.7 which decreased gradually to 1.9 (at week 2) and then 1.4 (at week 4) in Group A. In Group B, at baseline, the mean symptom severity 
Table I

Comparison VAS, symptom severity score and functional status score between the two groups

\begin{tabular}{|c|c|c|c|c|}
\hline & & Week 0 & Week 2 & Week 4 \\
\hline \multicolumn{5}{|c|}{ Visual analogue scale } \\
\hline Group A & & $6.0 \pm 1.3$ & $3.3 \pm 0.9$ & $2.7 \pm 0.9$ \\
\hline \multirow{2}{*}{ Group B } & & $6.4 \pm 1.1$ & $4.4 \pm 0.0$ & $3.2 \pm 1.1$ \\
\hline & $p$ value & $>0.05$ & $<0.001$ & $<0.05$ \\
\hline \multicolumn{5}{|c|}{ Symptom severity score } \\
\hline Group A & & $3.7 \pm 0.9$ & $1.9 \pm 0.7$ & $1.4 \pm 0.4$ \\
\hline \multirow[t]{2}{*}{ Group B } & & $3.8 \pm 0.9$ & $1.6 \pm 0.5$ & $1.3 \pm 0.4$ \\
\hline & $\mathrm{p}$ value & $>0.05$ & $<0.05$ & $>0.05$ \\
\hline \multicolumn{5}{|c|}{ Functional status score } \\
\hline Group A & & $3.9 \pm 0.9$ & $1.7 \pm 0.6$ & $1.3 \pm 0.6$ \\
\hline \multirow[t]{2}{*}{ Group B } & & $4.0 \pm 0.8$ & $2.3 \pm 0.6$ & $2.0 \pm 0.6$ \\
\hline & $p$ value & $>0.05$ & $<0.001$ & $<0.001$ \\
\hline
\end{tabular}

score was 3.8 which decreased gradually to 1.6 (at week 2) and then 1.3 (at week 4). At the initial stage, there was no statistical difference between the two groups $(p>0.05)$. But in week 2 there was highly significant statistical difference $(p<0.05)$. However, in week 4, there was no statistical difference between the two groups ( $p>0.05$ ).

In case of functional status score, at baseline, the mean functional status score was 3.9 which decreased gradually to 1.7 (at week 2) and then 1.3 (at week 4) in Group A. In Group B, at baseline, the mean functional status score was 4.0 which decreased gradually to 2.3 (at week 2) and then 2.0 (at week 4). At the initial stage, there was no statistical difference between the two groups regarding functional status score (p $>0.05$ ). But in week 2 and 4 , there were highly significant statistical difference regarding functional status score between the two groups $(\mathrm{p}<0.05)$

There was no statistical difference regarding the age, sex, handedness and duration of carpal tunnel syndrome between the two groups.

\section{Discussion}

There was an improvement in carpal tunnel syndrome after treatment in both the groups in the present study. The improvement appeared after one week. That is, intralesional steroid group and ultrasound therapy group, both began to improve after starting treatment. The difference of improvement between the two groups was found to begin at the end of week 2 . The improvement was continued throughout the whole period of the study. After completion of the treatment i.e. after end of week 4 there was a highly significant improvement in both groups. In comparison, between the two groups, a significant improvement of the carpal tunnel syndrome was found in the patients who received intralesional steroid plus wrist splint, exercise and naproxen sodium $500 \mathrm{mg}$ tablet twice daily.

Similar to this study, Huisstede et al. (2010) studied that strong and moderate evidence was found for the effectiveness of oral steroid injections, ultrasound, nocturnal splinting in the short -term. Also, moderate evidence was found for ultrasound in the midterm. With the exception of steroid injections, no long-term results were reported for any of these treatments. Moreover, although higher doses of steroid injections seem to be more effective in the midterm, the benefits of steroids injections were not maintained in the long-term.20 Although potential adverse effects to nerves and tendons with repeated injections have limited the value of this treatment.21, 22

In contrast to this result, Ebenbichler et al. (1998), concluded that ultrasound treatment may be similar in effectiveness to steroid injection or wrist splinting; improvements persisting for at least 6 months in most patients might even suggest the potential superiority of ultrasound treatment. $.23,24$

Carpal tunnel syndrome should be initially treated conservatively. Several authors declared that non-surgical methods are ineffective, some stated that local steroid injection has been proven to provide consistent and predictable short-term pain relieve. .25 While others stated that physical modalities could treat patients with carpal tunnel syndrome successfully and assist recoveries such as ultrasound,,$\underline{26}$ pulsed magnetic field,, 27 paraffin therapy, $2 \underline{28}$ low-level laser therapy, $\underline{29}$ exercises or splints. $\underline{30}$

According to this study intra-lesional corticosteroid injection improves VAS scores and Boston carpal tunnel questionnaire (BCTQ) either the symptom severity or functional capacity for mild to moderate carpal tunnel syndrome. The effect of corticosteroid in pain and inflammation control is well-studied. The effect of ultrasound therapy is not thermal, instead, it is supposed to facilitate microcirculation and endorphin secretion. In addition, hinder the enzymes that block pain enzymes leading to reduce pain and inflammation. 31

A study shows that the ultrasound therapy group showed improvement in pain-relieving 
and an increase in hand grip and pinch strength these can be attributed to stretching adhesions, increasing the space between the transverse carpal ligament and median nerve, and by reducing the compression and edema within the carpal tunnel. 32 These are in favor of this present study. The treatment of carpal tunnel syndrome with corticosteroid is effective in short and long-term follow-up. There are important reasons to minimize the amount of steroid used, and this study has shown that low dose hydrocortisone is as effective as higher doses of the same or alternative, longer acting and steroid preparation.

\section{Conclusion}

Significantly higher improvement is noticed in patients who received intralesional corticosteroid than ultrasound therapy as evidenced by improvement of VAS score and Boston carpal tunnel questionnaire.

\section{Ethical Issue}

A well-informed, voluntary, signed written consent was taken in Bangla from the study subjects before enrollment after convincing them that privacy, anonymity, and confidentiality of data information identifying any patient would be maintained strictly. Each patient enjoyed every right to participate or refuse or even withdraw from the study at any point in time. The protocol was approved by the Institutional Review Board of Bangabandhu Sheikh Mujib Medical University (BSMMU/2019/10890).

\section{Conflict of Interest}

Authors declare no conflict of interest.

\section{Acknowledgements}

We are grateful to physiotherapist Mr. Abul Kalam Azad for his kind cooperation. We are thankful for financial support from the Ministry of Science and Technology, Government of Bangladesh (Ref. No. 464/2019).

\section{References}

1. Bland JD. Treatment of carpal tunnel syndrome. Muscle Nerve. 2007; 36: 167-71.

2. Padua L, Padua R, Aprile I, D'Amico P, Tonali P. Carpal tunnel syndrome: Relationship between clinical and patient-oriented assessment. Clin Orthop. 2002; 395: 128-34.
3. Aroori S, Spence Roy AJ. Carpal tunnel syndrome. Ulster Med J. 2008; 77: 6-17.

4. Muller M, Tsui D, Schnurr R, Biddulph-Deisroth L, Hard J, MacDermid JC. Effectiveness of hand therapy interventions in primary management of carpal tunnel syndrome: A systematic review. J Hand Ther. 2004; 17: 210-28.

5. Shakoor MA, Islam MT, Salek AKM, Moyenuzzaman M. Effects of rehabilitation on the patients with chronic low back. Bangabandhu Sheikh Mujib Med Univ J. 2019; 12: 6-9.

6. Blanchard V, Barr S, Cerisola FL. The effectiveness of corticosteroid injections compared with physiotherapeutic interventions for adhesive capsulitis: A systematic review. Physiotherapy 2010; 96: 95-107.

7. Marshall SC, Tardif G, Ashworth NL. Local corticosteroid injection for carpal tunnel syndrome. Cochrane Database Syst Rev. 2007; 2.

8. Flondell M, Hofer M, Björk J, Atroshi I. Local steroid injection for moderately severe idiopathic carpal tunnel syndrome: Protocol of a randomized double-blind placebo-controlled trial. BMC Musculoskelet Disord. 2010; 11: 76.

9. Emran M, Ahmed SM, Hasan MI, Emran A. Occupation-related physical activities in osteoarthritis of the knee in female. Bangabandhu Sheikh Mujib Med Univ J. 2019; 12: 84-87.

10. Racasan O, Dubert TH. The safest location for steroid injection in the treatment of carpal tunnel syndrome. J Hand Surg Br. 2005; 30: 412-14.

11. Watson T. Electrotherapy e-book: Evidence-based practice. Elsevier Health Sciences, 2008.

12. Wong RA, Schumann B, Townsend R, Phelps CA. A survey of therapeutic ultrasound use by physical therapists who are orthopaedic certified specialists. Phys Ther. 2007; 87: 986-94.

13. Speed CA. Therapeutic ultrasound in soft tissue lesions. Rheumatology 2001; 40: 1331-36.

14. Fu SC, Shum WT, Hung LK, Wong MW, Qin L, Chan KM. Low-intensity pulsed ultrasound on tendon healing: A study of the effect of treatment duration and treatment initiation. Am J Sports Med. 2008; 36: 1742-49.

15. Korstjens CM, Van der Rijt RH, Albers GH, Semeins CM, Klein-Nulend J. Low-intensity pulsed ultrasound affects human articular chondrocytes in vitro. Med Biol Eng Comput. 2008; 46: 1263-70.

16. Rutjes AW, Nüesch E, Sterchi R, Jüni P. Therapeutic ultrasound for osteoarthritis of the knee or hip. Cochrane Database Syst Rev. 2010; 1.

17. Van den Bekerom MP, van der Windt DA, ter Riet G, van der Heijden GJ, Bouter LM. Therapeutic ultrasound for acute ankle sprains. Cochrane Database Syst Rev. 2011; 6.

18. Manente G, Torrieri F, Di Blasio F, Staniscia T, 
Romano F, Uncini A. An innovative hand brace for carpal tunnel syndrome: A randomized controlled trial. Muscle Nerv. 2001; 24: 1020-25.

19. Levine DW, Simmons BP, Koris MJ, Daltroy LH, Hohl GG, Fossel AH, Katz JN. A self-administered questionnaire for the assessment of severity of symptoms and functional status in carpal tunnel syndrome. J Bone Joint Surg. Am. 1993; 75: 1585-92.

20. Huisstede BM, Hoogvliet P, Randsdorp MS, Glerum S, van Middelkoop M, Koes BW. Carpal tunnel syndrome. Part I: Effectiveness of nonsurgical treatments- A systematic review. Arch Phys Medicine Rehabil. 2010; 91: 981-1004.

21. Burton RI, Littler J. Entrapment syndromes of the retinacular or restraining systems of the hand: Carpal tunnel syndrome. Curr Probl Surg. 1975; 12: 17.

22. McConnell JR, Bush DC. Intraneural steroid injection as a complication in the management of carpal tunnel syndrome: A report of three cases. Clin Orthop. 1990; 250: 181-84.

23. Edel H, Bergmann P. Studies on the effect of ultrasonics in different dosage on the the neuralconduction velocity in man. Arch Phys Ther Leipz. 1970; 22: 255-59.

24. Mayr H, Ammer K. Impulsgalvanisation und ultraschall zur therapie des carpal tunnel syndromes. Österr Z Phys Med. 1994; 4: 95-99.

25. Islam MT, Shakoor MA, Albers GH, Mahjabin A, Emran MA. Effects of intalesional platelet-rich plasma in the patients with lateral epicondylitis of elbow. Bangabandhu Sheikh Mujib Med Univ J. 2019; 12: 138-41.

26. Bakhtiary AH, Rashidy-Pour A. Ultrasound and laser therapy in the treatment of carpal tunnel syndrome. Aus J Physiother. 2004; 50: 147-51.

27. Dakowicz A, Kuryliszyn-Moskal A, KosztyłaHojna B, Moskal D, Latosiewicz R. Comparison of the long-term effectiveness of physiotherapy programs with low-level laser therapy and pulsed magnetic field in patients with carpal tunnel syndrome. Adv Med Sci. 2011; 56: 270-74.

28. Chang CW, Wang YC, Chang KF. A practical electrophysiological guide for non-surgical and surgical treatment of carpal tunnel syndrome. J Hand Surg. 2008; 33: 32-37.

29. Li ZJ, Wang Y, Zhang HF, Ma XL, Tian P, Huang Y. Effectiveness of low-level laser on carpal tunnel syndrome: A meta-analysis of previously reported randomized trials. Medicine 2016; 95: e4424.

30. Werner RA, Franzblau A, Gell N. Randomized controlled trial of nocturnal splinting for active workers with symptoms of carpal tunnel syndrome. Arch Phys Med Rehabil. 2005; 86: 1-7.

31. Ardic F, Soyupek F, Kahraman Y, Yorgancioglu R. The musculoskeletal complications seen in type II diabetics: Predominance of hand involvement. Clin Rheumatol. 2003; 22: 229-33.

32. Raeissadat A, Soltani ZR. Study of long-term effects of laser therapy versus local corticosteroid injection in patients with carpal tunnel syndrome. J Lasers Med Sci. 2010; 1: 24-30. 